\title{
Analysis on Factors Infecting Doctors' Job Burnout and Countermeasures
}

\author{
Jingsong Mei, Xiansong Li*, Jin Zhou, Kun Zhang \\ Medical Service, Jingzhou Central Hospital, The Second Clinical Medical College, Yangtze \\ University, Jingzhou, Hubei 434020,China. \\ *Corresponding author E-mail:6939904@qq.com
}

Keywords: doctors’ job burnout; influencing factor; countermeasure

\begin{abstract}
Objective: to discuss the factor influencing doctors' job burnout, and formulate the effective prevention and relief countermeasures. Method: 230 doctors from each clinical department of a Grade 3 and Class A hospital in Jingzhou City were chosen as the objects of investigation, and Maslach Burnout Inventory was used for questionnaire survey. Some doctors were chosen for in-depth interview. Statistics and analysis of the questionnaires and interviews were carried out. Results: in the job burnout of doctors from a Grade 3 and Class A hospital in Jingzhou City, severity rate of emotional exhaustion was as high as $51.3 \%$, significantly higher than that of emotional alienation and low sense of job achievement. Relevant influencing factors include social support, work pressure source and work pressure intensity. Conclusion: the occurrence rate of doctors' job burnout is high, and job burnout can be prevented and relieved from such aspects as gaining social support, creating favorable work environment, enhancing humanistic care and cultivating sense of profession.
\end{abstract}

Job burnout refers to individual state of physical and mental fatigue and exhaustion generated under heavy work pressure ${ }^{[1]}$. Doctors' responsibility is to heal the wounded and rescue the dying and they bears psychological stress heavier than common people. Besides, the long working hours and heavy workload aggravate doctors' physical burden. Under multiple pressures, doctors lose job enthusiasm, treat people indifferently and have low self-expectation and self-evaluation. To improve medical level and reduce medical risks, 230 doctors from each clinical department of a Grade 3 and Class A hospital in Jingzhou City were chosen as the objects of study.

\section{Data and Method}

\subsection{General data}

230 doctors from each clinical department of a Grade 3 and Class A hospital in Jingzhou City were chosen as the objects of study, including 127 male doctors and 103 female doctors. Their age

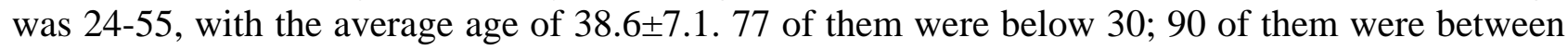
30 and 40; 40 of them were above 63.33 of them were single, and 197 of them were married. 148 of them had children, and 82 of them had no child. 189 of them were undergraduates, and 41 of 
them were postgraduates or above. 83 of them had junior job title; 79 of them had intermediate job title; 68 of them had senior job title. 75 of them worked for less than 5 years; 53 of them worked for 5-10 years; 55 of them worked for 11-20 years; 47 of them worked for more than 20 years.

\subsection{Method}

15 staffs were picked out from a Grade 3 and Class A hospital in Jingzhou City, and formed the investigation team after professional training. They were responsible for questionnaire survey and in-depth interview as well as data statistics and analysis.

Maslach Burnout Inventory (MBI), social support revalued scale (SSRS), work pressure source questionnaire and work pressure intensity questionnaire ${ }^{[2]}$. The investigation group was responsible for supervising and urging to fill in and take back the questionnaires. 230 questionnaires were taken back in this study.

Chief physicians, associate chief physicians, attending doctors and resident doctors were chosen as the in-depth interview objects to understand doctors' job burnout of the hospital and their opinion and views on job burnout as well as influencing factors.

\subsection{Observation indexes}

Score statistics for doctors' job burnout was conducted. If the score of emotional exhaustion exceeds 27, the score of emotional alienation exceeds 13 or the score of low sense of job achievement exceeds 39, this indicates the degree of doctors' job burnout is severe ${ }^{[3]}$. If the score of emotional exhaustion is less than 16, the score of emotional alienation is less than 6 or the score of low sense of job achievement is less than 31, this indicates the degree of doctors' job burnout is low. If the above conditions are not met, this indicates the degree of doctors' job burnout is moderate.

The correlation of job burnout with social support, work pressure source and work pressure intensity was analyzed.

\subsection{Statistical method}

SPSS19.0 software was used for statistical treatment. Enumeration data were expressed with number, and measurement data were expressed with mean \pm standard deviation. $\mathrm{X}^{2}$ test is applied for significance test of enumeration data. The correlation was analyzed with Pearson analysis. $\mathrm{P}<$ 0.05 means the difference has statistical significance.

\section{Results}

\subsection{Score of job burnout}

Among 230 clinical doctors, 51.3\% of them had severe emotional exhaustion, greatly higher than the severity rates of emotional alienation (25.7\%) and low sense of job achievement (23.9\%). The comparison differences were significant ( $\mathrm{X}^{2}$ values: 31.97and 9.60, $\mathrm{P}<0.05$ ). See Table 1 for details.

Table 1 Score statistics of doctors' job burnout (\%, No.)

\begin{tabular}{cccc}
\hline Dimension & Low & Moderate & Severe \\
\hline Emotional exhaustion & $18.7 \%(43)$ & $30.0 \%(69)$ & $51.3 \%(118)$ \\
Emotional alienation & $30.4 \%(70)$ & $43.9 \%(101)$ & $25.7 \%(59)$ \\
Low sense of job & $23.9 \%(55)$ & $39.1 \%(90)$ & $37.0 \%(85)$ \\
achievement & & & \\
\hline
\end{tabular}




\subsection{Relative factors analysis of job burnout}

The correlation between job burnout and social support was significant. Emotional exhaustion, emotional alienation and low sense of job achievement were negatively correlated with social support. Job burnout and pressure source were correlated. Emotional exhaustion and emotional alienation were positively correlated with workload, time allocation, diagnosis and treatment of patients, management and interpersonal relationship. Low sense of job achievement was positively correlated with diagnosis and treatment of patients, management and interpersonal relationship. Job burnout was correlated with work pressure intensity. Emotional exhaustion was positively correlated with total work pressure intensity, medical accident pressure intensity, workload pressure intensity, doctor-patient relationship pressure intensity, employment pressure intensity, and pressure intensity of work and family conflict. Emotional alienation was positively correlated with total work pressure intensity, workload pressure intensity and doctor-patient relationship pressure intensity. Low sense of job achievement was positively correlated with total work pressure intensity, and doctor-patient relationship pressure intensity. Correlation analysis had statistical significance $(\mathrm{P}<0.05)$, as shown in Table 2.

Table 2 Relative factors analysis of job burnout

\begin{tabular}{|c|c|c|c|c|}
\hline & Relative factor & Emotional exhaustion & Emotional alienation & $\begin{array}{l}\text { Low sense of job } \\
\text { achievement }\end{array}$ \\
\hline \multirow{5}{*}{ Social support } & Total score of social support & $-0.271 *$ & $-0.293^{*}$ & $-0.304 *$ \\
\hline & Objective support & $-0.162 *$ & $-0.218 *$ & $-0.258 *$ \\
\hline & Subjective support & $-0.201 *$ & $-0.214^{*}$ & $-0.199 *$ \\
\hline & Support availability & $-0.189 *$ & $-0.170^{*}$ & $-0.276^{*}$ \\
\hline & Work aspect & 0.016 & 0.007 & 0.015 \\
\hline \multirow{4}{*}{ Pressure source } & Workload and time allocation & $0.193^{*}$ & $0.223^{*}$ & 0.065 \\
\hline & $\begin{array}{l}\text { Work environment and } \\
\text { resource }\end{array}$ & 0.027 & 0.019 & 0.015 \\
\hline & $\begin{array}{c}\text { diagnosis and treatment of } \\
\text { patients }\end{array}$ & $0.404 *$ & $0.372 *$ & $0.228^{*}$ \\
\hline & $\begin{array}{l}\text { Management and } \\
\text { interpersonal relationship }\end{array}$ & $0.238^{*}$ & $0.143^{*}$ & $0.497 *$ \\
\hline \multirow{9}{*}{$\begin{array}{l}\text { Work pressure } \\
\text { intensity }\end{array}$} & Total work pressure intensity & $0.217^{*}$ & $0.164 *$ & $0.098^{*}$ \\
\hline & $\begin{array}{l}\text { Medical accident pressure } \\
\text { intensity }\end{array}$ & $0.205^{*}$ & 0.061 & 0.073 \\
\hline & Workload pressure intensity & $0.183^{*}$ & $0.171^{*}$ & 0.082 \\
\hline & $\begin{array}{l}\text { Doctor-patient relationship } \\
\text { pressure intensity }\end{array}$ & $0.304^{*}$ & $0.297 *$ & $0.178^{*}$ \\
\hline & $\begin{array}{l}\text { Occupational prestige } \\
\text { pressure intensity }\end{array}$ & 0.098 & -0.049 & 0.062 \\
\hline & $\begin{array}{l}\text { Employment pressure } \\
\text { intensity }\end{array}$ & $0.192 *$ & 0.047 & 0.052 \\
\hline & $\begin{array}{l}\text { Career development pressure } \\
\text { intensity }\end{array}$ & 0.067 & -0.041 & 0.058 \\
\hline & Role duty pressure intensity & 0.053 & -0.039 & 0.084 \\
\hline & $\begin{array}{l}\text { Pressure intensity of work } \\
\text { and family conflict }\end{array}$ & $0.163^{*}$ & 0.065 & 0.072 \\
\hline
\end{tabular}

$* \mathrm{P}<0.05$.

\section{Discussion}

Doctors' job burnout not just seriously affects doctors' physical and psychological health, but also leads to adverse medical events, reduces medical level ${ }^{[4]}$ and damages interests of patients and hospitals. Thus, targeted countermeasures must be taken for prevention and relief.

Based on domestic and overseas research status as well as the results of this study ${ }^{[5]}$, higher social support degree is, weaker doctors' job burnout is. Among the pressure sources, workload, 
time allocation, diagnosis and treatment of patients (especially), management and interpersonal relationship have great influence on job burnout. In work pressure intensity, doctor-patient relationship intensity is the main relevant factor. Based on the above results, the following countermeasures were formulated by the hospital:

(1) To gain social support

It is required to enhance communication and exchange among doctors, nurses and patients, and exhibit doctors' job content and workload ${ }^{[6]}$ to others through multiple ways so that others can have more understanding of doctors including their duties, efforts, pains and helplessness in the face of difficult miscellaneous diseases. Meanwhile, in the face of patients, it is required to introduce more about the diseases. The liabilities for the inability of treatment cannot be blamed for doctors. It is also required to construct the harmonious and tolerant doctor-patient relationship, and strive for extensive social support.

(2) To create favorable work environment

Doctors' work environment is special. They shuttle back and forth inpatient wards, operating rooms and consulting rooms every day. In the face of patients' pains, depression and dark environment, doctors' mental stress will increase ${ }^{[7]}$. In addition, the heavy workload will increase the possibility of job burnout. Therefore, the hospital should rationally allocate departments and medical workers according to practical number of patients to prevent overload work.

(3) To enhance humanistic care

The hospital should improve management and service functions of relevant departments, and do logistical support well. At the same time, the hospital should formulate fair, just and open career development and promotion mechanism ${ }^{[8]}$, and improve doctors' career expectations, which contributes to doctors' career development. In accordance with different abilities of doctors, different opportunities for learning and further study should be provided, and proper awards should be given according to work performance.

(4) To cultivate sense of profession

Vocational training should be provided for doctors at the regular interval. It is not just required to train professional theories and skills of diagnosis and treatment, but also required to cultivate the sense of profession, including job attitude, mentality, sense of responsibility and mental regulation so as to make the doctors own solid business ability, strong psychological bearing capability, positive and optimistic mentality and strong sense of responsibility.

In conclusion, the occurrence rate of doctors' job burnout is high. Job burnout can be prevented and relieved from such aspects as gaining social support, creating favorable work environment, enhancing humanistic care and cultivating sense of profession.

\section{References}

[1] Tian X, Liu C, Zou G, et al.Positive resources for combating job burnout among Chinese telephone operators: Resilience and psychological empowerment.Psychiatry Res. 2015 Aug 30;228(3):411-5.

[2] Arora, Manit,Diwan,et al. Prevalence and factors of burnout among Australian orthopaedic trainees: a crosssectional study[J].Journal of Orthopaedic Surgery,2014,22(03):374.

[3] Khamisa N, Oldenburg B, Peltzer K,et al.Work related stress, burnout, job satisfaction and general health of nurses.Int J Environ Res Public Health. 2015 Jan 12;12(1):652-66.

[4] Blake E Ashforth,Glen E Kreiner. Normalizing emotion in organizations [J]. Human Resource Management Review.2015, 12(2):215-235.

[5] Du H, Qin L, Jia H,et al .Relationship between job burnout and cognitive function and influencing factors of job burnout among medical staff].Zhonghua Lao Dong Wei Sheng Zhi Ye Bing Za Zhi. 2015 Sep;33(9):676-8.

[6] Brian A, Primack, Terri C.Dilmore, Galen E.Switzer,et al.Brief Report: Burnout Among Early Career Clinical Investigators [J]. Clinical and Translational Science, 2010, 03(4):186-188.

[7] Williams D1, Tricomi G, Gupta J, Janise A.Efficacy of burnout interventions in the medical education pipeline.Acad Psychiatry. 2015 Feb; 39(1):47-54. 
[8] Smith KJ1.Work-family conflict and job burnout among correctional staff: a comment on Lambert and Hogan (2010)1.Psychol Rep. 2011 Feb;108(1):23-6.

[9] Pustutka-Piwnik U, Ryn ZJ, Krzywoszański L, Stożek J.Burnout syndrome in physical therapists - demographic and organizational factors.Med Pr. 2014;65(4):453-62.

[10] Bakhos CT, Castillo-Sang M.How to balance family with career: A man's perspective.J Thorac Cardiovasc Surg. 2016 Aug;152(2):357-9. 